Jorge Mesquita Huet Machado ${ }^{1,2}$ Francisco Antonio de Castro Lacaz $^{1,3}$

\section{Respondendo a um chamamento!}

\author{
Answering a request!
}

${ }^{1}$ Associação Brasileira de PósGraduação em Saúde Coletiva - ABRASCO / GT Saúde do TrabaIhador.

2 Tecnologista em Saúde Pública da Fundação Oswaldo Cruz; assessor técnico do Departamento de Vigilância em Saúde Ambiental e Saúde do Trabalhador da Secretaria de Vigilância em Saúde do Ministério da Saúde.

${ }^{3}$ Professor Associado II do Departamento de Medicina Preventiva da Universidade Federal de São Paulo / Escola Paulista de Medicina.
Pioneira na publicação de artigos sobre estudos e pesquisas referentes às relações Trabalho-Saúde, a Revista Brasileira de Saúde Ocupacional (RBSO), periódico científico editado pela Fundação Jorge Duprat Figueiredo de Segurança e Medicina do Trabalho (Fundacentro), desde 1973, vem abordando temáticas importantes para a difusão das práticas relativas à saúde dos trabalhadores.

Assim, no editorial intitulado "A RBSO e seu compromisso com o campo da Saúde do Trabalhador" (ALGRANTI, E. et al. Revista Brasileira de Saúde Ocupacional, São Paulo, v. 34, n. 120, p. 104-105, jul/dez. 2009. Editorial.), a revista assume o posicionamento de estabelecer um diálogo com o campo Saúde do Trabalhador, dando sinais de uma clara abertura para novas abordagens. Até mesmo a proposta de mudança do nome da revista e a opção por sua manutenção, embora, de fato, não fosse a questão central da discussão travada pelo seu Conselho Editorial, ressalta a abertura de escopo acima referida.

Neste sentido, atenta ao aumento da produção científica no campo Saúde do Trabalhador, mas também à sua "fragmentação e dispersão", a política editorial agora adotada pela RBSO "[...] visa, [...], enfrentar este aspecto apontado, colocando-se como um lócus da produção acadêmica na área” (ALGRANTI, E. et al., Ibid., p. 104).

Mesmo mantendo seu nome, o que importa realmente é o compromisso da revista com o campo Saúde do Trabalhador e em "[...] consolidar seus objetivos e cumprir a missão de 'publicar artigos científicos relevantes para o desenvolvimento do conhecimento e para incrementar o debate teórico científico no campo da SST"” (ALGRANTI, E. et al., Ibid., p. 105). Este delineamento abre a perspectiva de um debate sobre a configuração das aproximações e diferenciações entre estes campos, tema que se coloca em especial relevância no Brasil pela coexistência de políticas que trazem essas denominações.

Diante deste chamamento, a Associação Brasileira de Pós-Graduação em Saúde Coletiva (Abrasco), através de seu Grupo de Trabalho em Saúde do Trabalhador, posiciona-se no sentido de considerá-lo um importante avanço, o que permite um diálogo cada vez mais profícuo, seja com os grupos acadêmicos em Saúde Coletiva que se dedicam à produção do conhecimento em Saúde do Trabalhador, seja com os profissionais de saúde, que, por todo o território nacional, desenvolvem suas atividades nos serviços voltados à atenção em Saúde do Trabalhador e que também expressam seus achados e reflexões nos Congressos e demais eventos promovidos pela Abrasco, com suas vivências para a produção de conhecimento no campo.

Dessa forma, a RBSO passa a ser um espaço privilegiado de publicação para a difusão do conhecimento nacional produzido pelos grupos e profissionais que vêm pensando a Saúde do Trabalhador no âmbito da Saúde Coletiva.

Assim, a Abrasco, através do GT de Saúde do Trabalhador, vem a público somar-se ao chamamento anunciado pelo Conselho Editorial da RBSO, visando estabelecer uma parceria promissora para ambos os lados, na perspectiva de contribuir para que o conhecimento produzido seja socializado, e que tal fato colabore para a elaboração de políticas sociais de abrangência nacional embasadas nas formulações do campo Saúde do Trabalhador. 